\title{
Theoretical study of the mechanism of proton transfer in tautomeric systems: Alloxan
}

\author{
RITA KAKKAR*, BHUPENDRA K SARMA and VANDANA KATOCH \\ Department of Chemistry, University of Delhi, Delhi 110 007, India \\ e-mail: rita_kakkar@vsnl.com
}

MS received 12 July 1999; revised 18 January 2000

\begin{abstract}
Semiempirical SCF-MO studies of tautomerism in alloxan preclude the possibility of direct proton transfer in the gas phase due to the strain in the four-centred transition state, in which the proton being transferred is forced to come close to the positively charged carbon atom at the opposite corner of the four-membered ring. However, in aqueous solution, the activation barrier reduces appreciably, not only due to reduction in strain, but also due to charge separation in the transition state, which is stabilized due to ionic resonance. The $\mathrm{N}-\mathrm{H}$ bond is almost broken, while the $\mathrm{O}-\mathrm{H}$ bond is only partially formed in the transition state. The other stabilizing effect in aqueous solution is due to bulk solvent dielectric effects, which stabilize the transition state to a greater extent due to its higher dipole moment. Although the transition states for proton transfer to the neighbouring oxygen atoms on either side have comparable energies, as the mechanisms of proton transfer leading to the formation of the 2-hydroxy and 4-hydroxy tautomers are similar, bulk solvent effects are larger in the latter due to the higher dipole moment of the transition state. The reason is the almost complete separation of the two entities, i.e. the alloxan anion and the hydronium ion in the latter case, indicating that in this case a dissociative mechanism of the kind encountered in acid-base equilibria is operating.
\end{abstract}

Keywords. Proton transfers; tautomerism; dissociative process; direct proton transfer.

\section{Introduction}

Recently, a lot of interest has been centred, not only on the possibility of tautomerism in various $\mathrm{N}$-heterocycles of biological interest, but also on the mechanism of proton transfer. In particular, the 2-pyridone-2-hydroxypyridine system has been the subject of much research on this subject ${ }^{1-4}$.

For this system, it was observed that the calculated barrier height is very large for the direct proton transfer process, suggesting that this mechanism does not operate. However, since actual bioprocesses usually occur in aqueous solution, solvent assistance may play a role in proton transfer by reducing the barrier height. The water molecule may bind with the heterocycle moiety, and facilitate the transfer of a proton by using its own hydrogens. In addition, the bulk solvent may also exert some influence on the barrier height. Hence,

*For correspondence 
we have to consider not only the role of a single water molecule in the transfer of the proton, but also the effect of the bulk solvent on barrier height.

The purpose of this work is to investigate the direct and solvent assisted mechanisms for proton transfer in a biologically active molecule, alloxan (see figure 1). We have recently studied this system in detail ${ }^{5}$. The biological activity of this compound, as well as its unique structure consisting of four keto groups, prompted us to undertake this study. It is of interest to examine whether differences arise in the mechanisms and activation barriers to the 1,2-hydrogen shifts in this case due to its unique structure in comparison with the 2-pyridone system.

We therefore examined different alternative pathways for the proton transfers. Our previous studies ${ }^{5}$ had indicated that the MNDO method ${ }^{6}$ is able to predict the relative tautomer energies in the case of alloxan, due to the absence of intramolecular hydrogen bonding in this case. Accordingly, we have used this method to calculate the barriers. However, since we have also investigated the role of the solvent water molecules in the proton transfer process, and since the MNDO method does not adequately reproduce hydrogen bonded structures with water, we have had to use an additional method of calculation. Since the AM1 method $^{7}$ was found to give good results for the monohydrate, we have used this method. For the sake of comparison, the results of PM3 calculations ${ }^{8}$ are also reported.

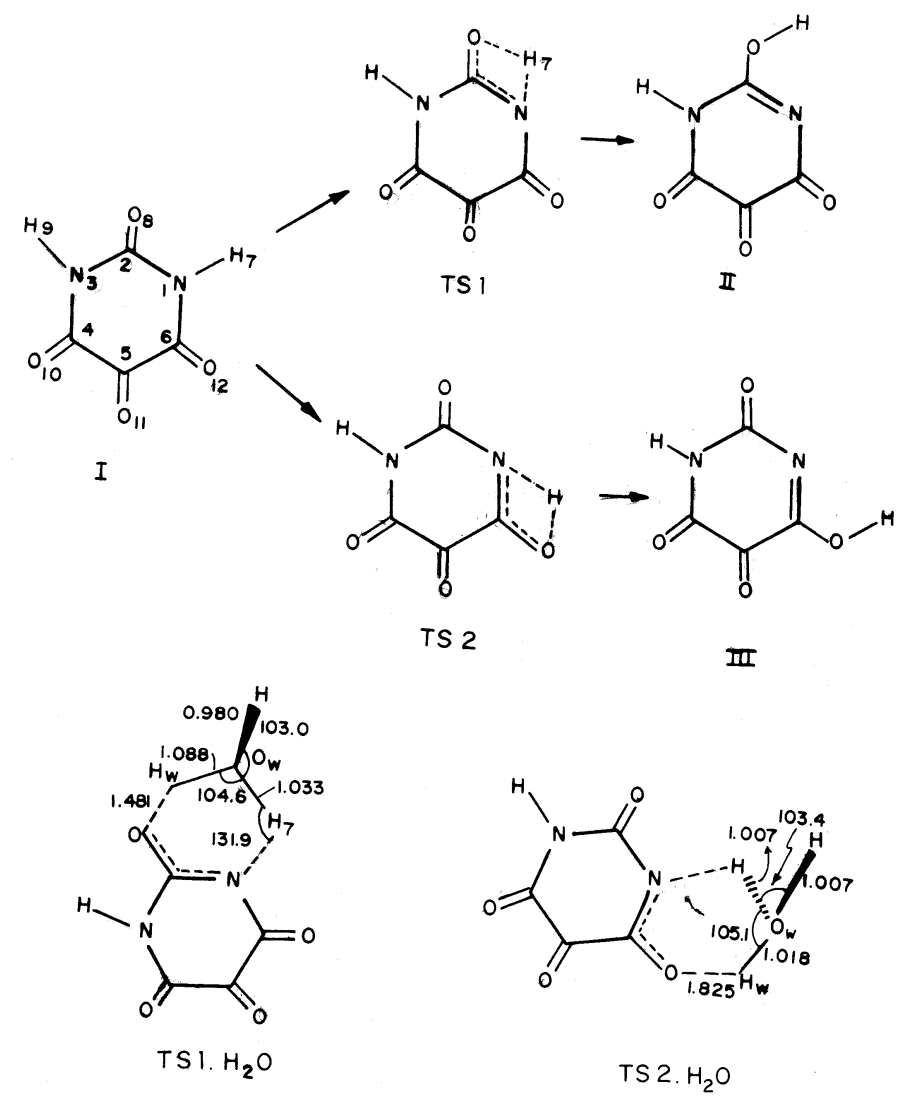

Figure 1. Reactions investigated and structures of transition states. 


\section{Computational details}

The MOPAC 6.12 program $^{9}$ was used for all the calculations. The keywords PRECISE and GNORM $=0.0$ were used to obtain all stationary points on the potential energy surfaces. The keyword SADDLE was used to obtain transition state structures, which were further refined using the eigenvalue following method ${ }^{10}$. The vibrational frequencies were calculated to confirm that, besides the requirement of zero norm of gradient, they had the requisite single imaginary vibrational frequency. The thermodynamic parameters were calculated by the standard procedure as implemented in MOPAC.

Solvent (water) effects were investigated in two steps. First, the effect of participation of a single water molecule in the supermolecule calculation was examined. Bulk solvent effects were then investigated within the framework of the continuum model using the COSMO (Conductor-like Screening Model) procedure ${ }^{11}$ implemented in MOPAC, with the dielectric constant taken as 78.4 for water at $298 \mathrm{~K}$.

\section{Results and discussion}

Since the relative tautomer energies had revealed that the tetraketo form is the most stable, followed by the monohydroxy forms, 4-hydroxy (III) and 2-hydroxy (II), we considered the transformations I $\leftrightarrow$ II and I $\leftrightarrow$ III (see figure 1).

\subsection{I $\leftrightarrow$ II Tautomerization}

For the I $\leftrightarrow$ II transformation, the calculated activation barriers are $71.3 \mathrm{kcal} / \mathrm{mol}$ (MNDO), $63.7 \mathrm{kcal} / \mathrm{mol}$ (AM1) and $49.9 \mathrm{kcal} / \mathrm{mol}$ (PM3). The structure of the transition state is depicted in figure 1 (TS1), and the optimized geometries, as calculated by the three methods, are given in table 1. It can be seen that these geometries are similar, except the $\mathrm{C}_{2}-\mathrm{N}_{3}$ bond distance, for which the PM3 value is larger than that calculated by the other two methods. We had seen ${ }^{12}$ that the PM3 method does not adequately take into account the interactions of the nitrogen atom with the adjacent carbonyl groups, and hence underestimates the double bond character of the $\mathrm{CN}$ bonds. Contrary to expectations, the four-centred transition states have planar structures.

The charge densities given in table 2 again show that the PM3 charge densities are not consistent with those calculated by the other methods, due to its underestimation of the delocalization of electron density from the carbonyl oxygens to the nitrogen atoms. Calculations on alloxan itself ${ }^{12}$ had shown that the MNDO and AM1 charge densities are in agreement with experimental charge densities obtained from X-ray crystallography ${ }^{13}$. Hence, the interactions will be discussed in terms of the AM1 charge densities.

It is found that the nitrogen $\left(\mathrm{N}_{1}\right)$ from which the hydrogen migrates becomes more negative in the transition state, while the migrating hydrogen $\left(\mathrm{H}_{7}\right)$ becomes more positively charged, due to its state of simultaneous bonding to two electronegative atoms, nitrogen and oxygen. The opposite carbon $\left(\mathrm{C}_{2}\right)$ in the four-membered ring is also positively charged. This has an important consequence. The energy of the transition state is high, not only because of the strain in the four-membered ring, but also because of the interatomic repulsion between the two oppositely charged atoms, which are forced to approach within $1.765 \AA$ of each other in the transition state. The positive charge on the migrating proton confirms that this is a proton transfer reaction, as opposed to a hydrogen transfer process. 
Table 1. Calculated structure parameters of the transition state connecting tautomers I and II (TS1) and its water complex ${ }^{\mathrm{a}}$.

\begin{tabular}{|c|c|c|c|c|c|}
\hline \multirow[b]{2}{*}{ Parameter } & \multicolumn{2}{|c|}{ TS1 } & \multicolumn{3}{|c|}{ TS1. $\mathrm{H}_{2} \mathrm{O}$} \\
\hline & MNDO & AM1 & PM3 & AM1 & PM3 \\
\hline \multicolumn{6}{|l|}{ Bonds $(\AA)$} \\
\hline $\mathrm{C}_{2} \mathrm{~N}_{1}$ & $1 \cdot 370$ & $1 \cdot 366(1 \cdot 377)$ & $1 \cdot 367$ & $1 \cdot 358$ & $1 \cdot 360$ \\
\hline $\mathrm{N}_{3} \mathrm{C}_{2}$ & $1 \cdot 371$ & $1 \cdot 375(1 \cdot 374)$ & $1 \cdot 392$ & $1 \cdot 404$ & 1.407 \\
\hline $\mathrm{C}_{4} \mathrm{~N}_{3}$ & 1.431 & $1.411(1.397)$ & 1.438 & $1 \cdot 396$ & 1.429 \\
\hline $\mathrm{C}_{5} \mathrm{C}_{4}$ & $1 \cdot 543$ & $1.533(1.530)$ & $1 \cdot 538$ & $1 \cdot 526$ & 1.532 \\
\hline $\mathrm{C}_{6} \mathrm{~N}_{1}$ & $1 \cdot 393$ & $1 \cdot 380(1 \cdot 363)$ & $1 \cdot 412$ & $1 \cdot 377$ & 1.413 \\
\hline $\mathrm{C}_{6} \mathrm{C}_{5}$ & $1 \cdot 542$ & $1.538(1.534)$ & $1 \cdot 539$ & $1 \cdot 531$ & 1.533 \\
\hline $\mathrm{H}_{7} \mathrm{~N}_{1}$ & $1 \cdot 357$ & $1.416(1.451)$ & $1 \cdot 505$ & $1 \cdot 810$ & 1.734 \\
\hline $\mathrm{O}_{8} \mathrm{C}_{2}$ & $1 \cdot 281$ & $1 \cdot 307(1 \cdot 304)$ & $1 \cdot 282$ & $1 \cdot 296$ & $1 \cdot 286$ \\
\hline $\mathrm{O}_{8} \mathrm{H}_{7}$ & $1 \cdot 365$ & $1.389(1.417)$ & 1.420 & $2 \cdot 511$ & $2 \cdot 505$ \\
\hline $\mathrm{H}_{9} \mathrm{~N}_{3}$ & 1.006 & $0.997(1.005)$ & $0 \cdot 997$ & $0 \cdot 997$ & 0.999 \\
\hline $\mathrm{O}_{10} \mathrm{C}_{4}$ & $1 \cdot 218$ & $1.233(1.242)$ & $1 \cdot 211$ & $1 \cdot 237$ & $1 \cdot 214$ \\
\hline $\mathrm{O}_{11} \mathrm{C}_{5}$ & $1 \cdot 217$ & $1.222(1.226)$ & $1 \cdot 204$ & $1 \cdot 223$ & 1.205 \\
\hline $\mathrm{O}_{12} \mathrm{C}_{6}$ & $1 \cdot 221$ & $1.235(1.251)$ & $1 \cdot 210$ & $1 \cdot 241$ & $1 \cdot 213$ \\
\hline
\end{tabular}

Bond angles $\left(^{\circ}\right)$

$\begin{array}{lrcrrr}\mathrm{N}_{3} \mathrm{C}_{2} \mathrm{~N}_{1} & 125 \cdot 3 & 127 \cdot 4(127 \cdot 3) & 126 \cdot 6 & 124 \cdot 3 & 125 \cdot 1 \\ \mathrm{C}_{4} \mathrm{~N}_{3} \mathrm{C}_{2} & 119 \cdot 7 & 118 \cdot 1(118 \cdot 2) & 117 \cdot 9 & 121 \cdot 2 & 120 \cdot 1 \\ \mathrm{C}_{5} \mathrm{C}_{4} \mathrm{~N}_{3} & 117 \cdot 1 & 118 \cdot 1(118 \cdot 5) & 119 \cdot 0 & 117 \cdot 5 & 118 \cdot 2 \\ \mathrm{C}_{6} \mathrm{C}_{5} \mathrm{C}_{4} & 119 \cdot 0 & 118 \cdot 5(117 \cdot 9) & 117 \cdot 7 & 116 \cdot 8 & 116 \cdot 5 \\ \mathrm{H}_{7} \mathrm{~N}_{1} \mathrm{C}_{2} & 78 \cdot 7 & 78 \cdot 7(78 \cdot 8) & 78 \cdot 7 & 103 \cdot 9 & 106 \cdot 5 \\ \mathrm{O}_{8} \mathrm{C}_{2} \mathrm{~N}_{3} & 133 \cdot 0 & 129 \cdot 6(128 \cdot 8) & 128 \cdot 6 & 116 \cdot 3 & 117 \cdot 3 \\ \mathrm{H}_{9} \mathrm{~N}_{3} \mathrm{C}_{2} & 119 \cdot 4 & 120 \cdot 6(120 \cdot 5) & 120 \cdot 3 & 118 \cdot 8 & 119 \cdot 6 \\ \mathrm{O}_{10} \mathrm{C}_{4} \mathrm{~N}_{3} & 117 \cdot 5 & 119 \cdot 0(120 \cdot 2) & 115 \cdot 5 & 119 \cdot 9 & 116 \cdot 1 \\ \mathrm{O}_{11} \mathrm{C}_{5} \mathrm{C}_{4} & 119 \cdot 0 & 119 \cdot 2(120 \cdot 0) & 119 \cdot 9 & 120 \cdot 1 & 120 \cdot 6 \\ \mathrm{O}_{12} \mathrm{C}_{6} \mathrm{~N}_{1} & 121 \cdot 6 & 124 \cdot 4(123 \cdot 8) & 119 \cdot 3 & 121 \cdot 9 & 131.9\end{array}$

Dihedral angles $\left(^{\circ}\right)$

$\begin{array}{lrcrrr}\mathrm{C}_{4} \mathrm{~N}_{3} \mathrm{C}_{2} \mathrm{~N}_{1} & 0 \cdot 0 & 0 \cdot 0(-0 \cdot 2) & 0 \cdot 0 & -0 \cdot 9 & -1 \cdot 3 \\ \mathrm{C}_{5} \mathrm{C}_{4} \mathrm{~N}_{3} \mathrm{C}_{2} & 0 \cdot 0 & 0 \cdot 0(-0 \cdot 1) & 0 \cdot 0 & -0 \cdot 3 & -1 \cdot 1 \\ \mathrm{C}_{6} \mathrm{C}_{5} \mathrm{C}_{4} \mathrm{~N}_{3} & 0 \cdot 0 & 0 \cdot 0(0 \cdot 4) & -0 \cdot 1 & 1 \cdot 6 & 4 \cdot 2 \\ \mathrm{H}_{7} \mathrm{~N}_{1} \mathrm{C}_{2} \mathrm{~N}_{3} & 180 \cdot 0 & 180 \cdot 0(180 \cdot 0) & 180 \cdot 0 & 176 \cdot 3 & 176 \cdot 9 \\ \mathrm{O}_{8} \mathrm{C}_{2} \mathrm{~N}_{3} \mathrm{C}_{4} & 180 \cdot 0 & 180 \cdot 0(179 \cdot 8) & 180 \cdot 0 & 179 \cdot 9 & 179 \cdot 6 \\ \mathrm{H}_{9} \mathrm{~N}_{3} \mathrm{C}_{2} \mathrm{~N}_{1} & 180 \cdot 0 & 180 \cdot 0(179 \cdot 6) & 180 \cdot 0 & 179 \cdot 3 & 178 \cdot 7 \\ \mathrm{O}_{10} \mathrm{C}_{4} \mathrm{~N}_{3} \mathrm{C}_{2} & 180 \cdot 0 & 180 \cdot 0(180 \cdot 0) & 180 \cdot 0 & 179 \cdot 8 & 179 \cdot 3 \\ \mathrm{O}_{11} \mathrm{C}_{5} \mathrm{C}_{4} \mathrm{~N}_{3} & 180 \cdot 0 & -179 \cdot 0(-179 \cdot 5) & 179 \cdot 9 & 181 \cdot 6 & 184 \cdot 5 \\ \mathrm{O}_{12} \mathrm{C}_{6} \mathrm{~N}_{1} \mathrm{C}_{2} & 180 \cdot 0 & 180 \cdot 0(180 \cdot 0) & 180 \cdot 0 & 180 \cdot 9 & 183 \cdot 0\end{array}$

${ }^{a}$ See figure 1. Values in parentheses are the AM1 geometries for the solution phase molecule

Better insight into the nature of the interactions present in the transition state can be obtained from a consideration of the natures of the frontier orbitals. As in the case of the equilibrium structures of alloxan and its tautomeric forms ${ }^{5}$, the transition state has a low energy lowest unoccupied molecular orbital, LUMO (energy $=-1.732 \mathrm{eV}$ ), which is the $\mathrm{C}_{5}=\mathrm{O}_{11} \pi^{*}$ orbital, with some contribution from the $\mathrm{C}_{4}=\mathrm{O}_{10} \pi^{*}$ orbital. The highest 
Table 2. Calculated partial charge distributions for the transition states TS1 and TS1. $\mathbf{H}_{2} \mathrm{O}^{\mathrm{a}}$.

\begin{tabular}{|c|c|c|c|c|c|}
\hline \multirow[b]{2}{*}{ Atom } & \multicolumn{3}{|c|}{ TS1 } & \multicolumn{2}{|c|}{ TS1. $\mathrm{H}_{2} \mathrm{O}$} \\
\hline & MNDO & AM1 & PM3 & AM1 & PM3 \\
\hline $\mathrm{N}_{1}$ & -0.529 & $-0.458(-0.474)$ & $-0 \cdot 366$ & -0.524 & $-0 \cdot 474$ \\
\hline $\mathrm{C}_{2}$ & $0 \cdot 429$ & $0.343(0.428)$ & $0 \cdot 212$ & $0 \cdot 382$ & $0 \cdot 275$ \\
\hline $\mathrm{N}_{3}$ & $-0 \cdot 354$ & $-0 \cdot 326(-0 \cdot 284)$ & $0 \cdot 061$ & $-0 \cdot 363$ & $0 \cdot 015$ \\
\hline $\mathrm{C}_{4}$ & $0 \cdot 324$ & $0 \cdot 260(0 \cdot 368)$ & $0 \cdot 183$ & $0 \cdot 257$ & $0 \cdot 185$ \\
\hline $\mathrm{C}_{5}$ & $0 \cdot 189$ & $0.163(0.270)$ & $0 \cdot 214$ & $0 \cdot 158$ & $0 \cdot 213$ \\
\hline $\mathrm{C}_{6}$ & $0 \cdot 329$ & $0.278(0.362)$ & $0 \cdot 273$ & $0 \cdot 269$ & $0 \cdot 276$ \\
\hline $\mathrm{H}_{7}$ & $0 \cdot 375$ & $0.427(0.508)$ & $0 \cdot 354$ & $0 \cdot 354$ & $0 \cdot 306$ \\
\hline $\mathrm{O}_{8}$ & $-0 \cdot 339$ & $-0 \cdot 346(-0.421)$ & $-0 \cdot 356$ & -0.492 & $-0 \cdot 455$ \\
\hline $\mathrm{H}_{9}$ & $0 \cdot 236$ & $0.279(0.333)$ & $0 \cdot 123$ & $0 \cdot 262$ & $0 \cdot 121$ \\
\hline $\mathrm{O}_{10}$ & $-0 \cdot 243$ & $-0.238(-0.386)$ & $-0 \cdot 264$ & $-0 \cdot 273$ & $-0 \cdot 284$ \\
\hline $\mathrm{O}_{11}$ & $-0 \cdot 161$ & $-0.138(-0.254)$ & -0.171 & $-0 \cdot 156$ & $-0 \cdot 182$ \\
\hline $\mathrm{O}_{12}$ & $-0 \cdot 256$ & $-0.244(-0.449)$ & $-0 \cdot 264$ & $-0 \cdot 285$ & $-0 \cdot 288$ \\
\hline
\end{tabular}

${ }^{a}$ See figure 1. Values in parentheses are the AM1 charge densities for the solution phase molecules

occupied molecular orbital (HOMO) is basically an oxygen $\left(\mathrm{O}_{11}\right)$ nonbonding orbital $(62 \%)$ in which the $\mathrm{N}_{1}, \mathrm{C}_{5}$, and $\mathrm{O}_{12}$ atoms also participate. It has higher energy than alloxan itself, showing that the ionization potential decreases in the transition state.

The imaginary frequencies in the transition state are 2490, 2201, and $1957 \mathrm{~cm}^{-1}$ (see table 3), as calculated by the MNDO, AM1 and PM3 methods, respectively, and reflect the overestimation of frequencies by the MNDO method, which need a correction of about $10 \%$. The negative frequency corresponds to the $\mathrm{N}-\mathrm{H}-\mathrm{O}$ stretching. The entropy of activation is small and positive $(\approx 4 \mathrm{cal} / \mathrm{deg} / \mathrm{mol})$ since the bonding is weaker in the transition state.

The calculated bond orders show that, in the four-centred structure (see figure 1), the $\mathrm{C}_{2}-\mathrm{N}_{1}, \mathrm{~N}_{1}-\mathrm{H}_{7}, \mathrm{O}_{8}-\mathrm{H}_{7}$ and $\mathrm{C}_{2}=\mathrm{O}_{8}$ bond orders are respectively, 1.245, 0.341, 0.429, and 1.384 , signifying that the $\mathrm{C}=\mathrm{O}$ and $\mathrm{N}-\mathrm{H}$ bonds are half broken and the incipient $\mathrm{O}-\mathrm{H}$ bond is also half formed. In fact, the calculated valency of $\mathrm{H}_{7}$ is only $0 \cdot 860$, again signifying that it is like a proton.

It is also instructive to examine whether a hydrogen-bonded structure with water helps in the proton transfer by decreasing the activation barrier. It was found that the hydrogen bonded alloxan structure (see figure 1) is stabilized by $6.3 \mathrm{kcal} / \mathrm{mol}$. The 2-hydroxy tautomer is stabilized by $6.1 \mathrm{kcal} / \mathrm{mol}$. However, the transition state is stabilized by $26.1 \mathrm{kcal} / \mathrm{mol}$. Thus, intervention of one water molecule in the supermolecule calculation brings down the activation barrier considerably. This is in agreement with ab initio calculations ${ }^{1,2}$. Using the canonical variational transition state theory (CVT) with multidimensional semiclassical tunneling corrections, Bell and Truong ${ }^{14}$ recently calculated thermal rate constants of the gas phase and water assisted tautomerizations in formamidine. Their calculations yielded a value of $26.9 \mathrm{kcal} / \mathrm{mol}$ for the lowering of the classical barrier on addition of a water molecule to the gas phase molecule.

The structure of the alloxan-water complex is shown in figure 1 and the geometries are given in table 1 . The AM1 geometries are in best agreement with the ab initio results ${ }^{1}$ 
Table 3. Calculated tautomerization energetics and activation parameters of the ground state intramolecular proton transfer reaction of alloxan at $298 \mathrm{~K}$ in the vapour phase $^{\mathrm{a}}$.

\begin{tabular}{|c|c|c|c|c|c|c|}
\hline Process & Method & $\Delta H$ & $\Delta H^{*}$ & $\Delta S^{*}$ & $\Delta G^{*}$ & $v^{*}$ \\
\hline \multirow[t]{3}{*}{ I-II } & MNDO & $4 \cdot 6$ & 71.2 & $3 \cdot 4$ & $70 \cdot 2$ & 2490 \\
\hline & AM1 & $18 \cdot 0(16 \cdot 7)$ & $63 \cdot 8(63 \cdot 0)$ & $3 \cdot 6$ & $62 \cdot 7$ & 2201 \\
\hline & PM3 & $12 \cdot 9$ & $49 \cdot 9$ & $4 \cdot 3$ & $48 \cdot 6$ & 1957 \\
\hline \multirow{2}{*}{ I-II $\left(\mathbf{H}_{\mathbf{2}} \mathbf{O}\right)$} & AM1 & $16 \cdot 1$ & $43 \cdot 9$ & $-6 \cdot 7$ & $45 \cdot 9$ & 988 \\
\hline & PM3 & $10 \cdot 0$ & $32 \cdot 4$ & $-9 \cdot 6$ & $35 \cdot 4$ & 1661 \\
\hline \multirow[t]{3}{*}{ I-III } & MNDO & $2 \cdot 7$ & $69 \cdot 3$ & 1.5 & $68 \cdot 8$ & 2510 \\
\hline & AM1 & $14.9(14.7)$ & $65 \cdot 1(65 \cdot 2)$ & 1.6 & $64 \cdot 6$ & 2224 \\
\hline & PM3 & 11.4 & $49 \cdot 0$ & 1.8 & $48 \cdot 5$ & 1964 \\
\hline \multirow[t]{2}{*}{ I-III ( $\left.\mathbf{H}_{2} \mathbf{O}\right)$} & AM1 & $15 \cdot 2$ & 45.3 & $-4 \cdot 8$ & $46 \cdot 7$ & 311 \\
\hline & PM3 & $11 \cdot 1$ & $31 \cdot 8$ & $-10 \cdot 8$ & $35 \cdot 0$ & 487 \\
\hline
\end{tabular}

${ }^{\mathrm{a}} \Delta H$, tautomerization energy $(\mathrm{kcal} / \mathrm{mol}) ; \Delta H^{*}$, activation enthalpy $(\mathrm{kcal} / \mathrm{mol}) ; \Delta S^{*}$, activation entropy (cal/mol/deg.); $\Delta G^{*}$, free energy of activation $(\mathrm{kcal} / \mathrm{mol}) ; v^{*}$, frequency of imaginary vibration interconverting reactants and products $\left(\mathrm{cm}^{-1}\right)$. Values in parentheses are the solution phase activation parameters.

on the 2-pyridone system. Complexation with water has a significant effect on the geometry of the transition state, and the charge densities on the atoms involved in the proton transfer process $\left(\mathrm{N}_{1}, \mathrm{C}_{2}, \mathrm{H}_{7}\right.$ and $\left.\mathrm{O}_{8}\right)$ are also different. Again the PM3 charge densities are unrealistic. Moreover, the geometries (table 1) and charge densities (table 2) of the water-complexed transition state reveal an interesting phenomenon. Whereas the $\mathrm{N}-\mathrm{H}$ bond is already broken (bond order $=0.072$ ), the $\mathrm{O}-\mathrm{H}$ bond is only partially formed (bond order $=0 \cdot 212$ ). The total valency of the water oxygen is $2 \cdot 46$, reflecting its bonding to three hydrogen atoms, akin to a hydronium ion. Thus, there is charge separation in the transition state, which is stabilized not only because of the easing of strain from the fourcentred transition state structure for the direct process, but also due to the resonance stabilization of the hydrogen bonds. The importance of the dipolar resonance structure in the presence of the solvent (water) can be seen from the enhanced dipole moment $(7.57 \mathrm{D}$ as compared with $3.61 \mathrm{D}$ for the transition state for the direct process, see table 4). This has a further consequence. The effect of bulk solvent is to reduce its energy by a factor proportional to the square of its dipole moment. Hence, the presence of the bulk solvent reduces the tautomerization energy since the dipole moment of the tautomer (II) is higher than that of the trioxo form, but reduces the activation barrier to a larger extent owing to the much higher value of the dipole moment of the corresponding transition state (see table 4).

However, since it has been observed ${ }^{15,16}$ that the solvent reaction field has a considerable effect on the dipole moment of the solute, more precise calculations were undertaken using the polarizable continuum model ${ }^{11}$. These revealed that the bulk solvent increases the dipole moments of the bare molecules (see table 4) to almost double their values in the gas phase. To analyse the contribution of dielectric effects and the energy lowering due to solute geometry relaxation, these two respective contributions were separately evaluated. It is found that solute relaxation contributes little $(0.5-$ $1.0 \mathrm{cal} / \mathrm{mol}$ ) to the lowering of energy, although considerable changes in the geometry of the transition state are observed in solution. As expected, the changes involve the 
Table 4. Gas and solution phase dipole moments and the interaction energies with water ${ }^{\mathrm{a}}$.

\begin{tabular}{lcccc}
\hline Solute & $\mu_{\text {gas }}$ & $\mu_{\text {soln }}$ & $-E_{\text {diel }}$ & $-E_{\text {int }}$ \\
\hline I & 1.71 & $3 \cdot 07$ & $26 \cdot 8$ & $27 \cdot 4$ \\
II & 4.86 & $9 \cdot 05$ & 27.6 & $28 \cdot 7$ \\
TS1 & 3.61 & 6.80 & $27 \cdot 1$ & $28 \cdot 1$ \\
III & 1.69 & $3 \cdot 18$ & $26 \cdot 7$ & $27 \cdot 5$ \\
TS2 & 0.95 & $2 \cdot 07$ & 26.5 & $27 \cdot 3$ \\
\hline
\end{tabular}

${ }^{\mathrm{a}} \mu_{\text {gas }}$, gas phase dipole moment (Debye); $\mu_{\text {soln }}$, solution phase dipole moment (Debye); $E_{\text {diel }}$, energy lowering due to dielectric screening; and $E_{\text {int }}$, net energy of stabilization in water $(\mathrm{kcal} / \mathrm{mol})$. Solvent dielectric constant is taken as $78 \cdot 4$, and AM1 values are given.

carbon-nitrogen bonds, the carbonyl bonds and the nitrogen-hydrogen bonds. In particular, the $\mathrm{N}_{1}-\mathrm{H}_{7}$ bond (figure 1) length increases by $0.04 \AA$ (see table 1), and the transition state becomes nonplanar.

The calculated partial charge densities also change substantially, increasing the dipole moments. In particular, the negative charges on the oxygens increase.

The thermodynamic parameters listed in table 3 show some interesting aspects. First, the effect of solvation is to reduce the tautomerization energy and the activation barrier. Entropy changes are small and positive for the direct process, but relatively larger for the solvent-assisted process. However, in this case, the entropy changes are negative, signifying that, while the alloxan-water complex is weak, the bonding with water is stronger for the transition state, in which the water molecule moves closer to the alloxan moiety in order to facilitate the proton transfer.

Table 3 indicates another interesting fact. The imaginary frequency of the transition state for the solvent assisted process is significantly lower than that for the direct process. In the latter process, the $\mathrm{N}_{1}-\mathrm{H}_{7}-\mathrm{O}_{8}$ stretching mode is responsible for the proton transfer, while, in the former, it is the $\mathrm{H}_{w} \mathrm{O}_{w} \mathrm{H}_{7}$ bending mode which is the reaction coordinate.

The HOMO, according to AM1 calculations, is a nonbonding oxygen orbital, while the LUMO is the $\mathrm{C}_{5} \mathrm{O}_{11} \pi^{*}$ orbital. The PM3 HOMO is an out-of-plane orbital involving the nitrogen lone pairs.

\subsection{I $I \leftrightarrow I I I$ transformation}

For proton transfer from $\mathrm{N}_{1}$ to $\mathrm{C}_{6}$ resulting in the formation of the 4-hydroxy tautomer, the conclusions are similar, except for the following.

(i) The bond lengths in the transition states for the direct and the solvent assisted processes are similar (see table 5).

(ii) The dipole moment of the transition state (TS2) for the direct process is quite small (0.92 D), but increases to 7.97 D on solvent participation.

(iii) The tautomerization energy is smaller as compared to the previous case; the activation barriers are similar, except that AM1 predicts a slightly higher activation barrier, while the PM3 barrier is slightly lower. The imaginary frequency for the solventassisted process is extremely low (see table 3 ). 
Table 5. Calculated structure parameters of the transition state connecting tautomers I and III (TS2) and its water complex ${ }^{\mathrm{a}}$.

\begin{tabular}{|c|c|c|c|c|c|}
\hline \multirow[b]{2}{*}{ Parameter } & \multicolumn{3}{|c|}{ TS2 } & \multicolumn{2}{|c|}{ TS2. $\mathrm{H}_{2} \mathrm{O}$} \\
\hline & MNDO & AM1 & PM3 & AM1 & PM3 \\
\hline \multicolumn{6}{|l|}{ Bonds $(\AA)$} \\
\hline $\mathrm{C}_{2} \mathrm{~N}_{1}$ & $1 \cdot 398$ & $1 \cdot 402(1 \cdot 392)$ & 1.422 & $1 \cdot 394$ & 1.413 \\
\hline $\mathrm{N}_{3} \mathrm{C}_{2}$ & 1.430 & $1.428(1.419)$ & 1.442 & 1.427 & 1.437 \\
\hline $\mathrm{C}_{4} \mathrm{~N}_{3}$ & 1.411 & $1.389(1.381)$ & 1.421 & $1 \cdot 385$ & 1.416 \\
\hline $\mathrm{C}_{5} \mathrm{C}_{4}$ & $1 \cdot 537$ & $1.531(1.530)$ & 1.533 & $1 \cdot 525$ & 1.529 \\
\hline $\mathrm{C}_{6} \mathrm{~N}_{1}$ & $1 \cdot 362$ & $1 \cdot 344(1 \cdot 346)$ & $1 \cdot 353$ & $1 \cdot 341$ & 1.379 \\
\hline $\mathrm{C}_{6} \mathrm{C}_{5}$ & $1 \cdot 501$ & $1.492(1.493)$ & $1 \cdot 502$ & $1 \cdot 519$ & 1.519 \\
\hline $\mathrm{H}_{7} \mathrm{~N}_{1}$ & $1 \cdot 352$ & $1.419(1.464)$ & $1 \cdot 505$ & $2 \cdot 250$ & 1.958 \\
\hline $\mathrm{O}_{8} \mathrm{C}_{2}$ & $1 \cdot 221$ & $1 \cdot 241(1 \cdot 256)$ & $1 \cdot 213$ & $1 \cdot 248$ & $1 \cdot 220$ \\
\hline $\mathrm{H}_{9} \mathrm{~N}_{3}$ & $1 \cdot 008$ & $1.000(1.005)$ & 1.000 & 0.998 & $1 \cdot 000$ \\
\hline $\mathrm{O}_{10} \mathrm{C}_{4}$ & $1 \cdot 223$ & $1 \cdot 238(1 \cdot 248)$ & $1 \cdot 215$ & $1 \cdot 241$ & $1 \cdot 217$ \\
\hline $\mathrm{O}_{11} \mathrm{C}_{5}$ & $1 \cdot 215$ & $1 \cdot 219(1 \cdot 222)$ & $1 \cdot 202$ & $1 \cdot 223$ & $1 \cdot 205$ \\
\hline $\mathrm{O}_{12} \mathrm{C}_{6}$ & $1 \cdot 275$ & $1.292(1.291)$ & $1 \cdot 273$ & $1 \cdot 276$ & $1 \cdot 243$ \\
\hline $\mathrm{O}_{12} \mathrm{H}_{7}$ & $1 \cdot 364$ & $1.406(1.437)$ & 1.425 & $3 \cdot 084$ & $2 \cdot 313$ \\
\hline \multicolumn{6}{|c|}{ Bond angles $\left(^{\circ}\right)$} \\
\hline $\mathrm{N}_{3} \mathrm{C}_{2} \mathrm{~N}_{1}$ & $114 \cdot 1$ & $116 \cdot 9(118 \cdot 7)$ & $116 \cdot 9$ & $120 \cdot 5$ & $120 \cdot 3$ \\
\hline $\mathrm{C}_{4} \mathrm{~N}_{3} \mathrm{C}_{2}$ & $127 \cdot 2$ & $124 \cdot 8(123 \cdot 5)$ & $123 \cdot 8$ & $123 \cdot 3$ & $122 \cdot 7$ \\
\hline $\mathrm{C}_{5} \mathrm{C}_{4} \mathrm{~N}_{3}$ & $117 \cdot 4$ & $118 \cdot 8(119 \cdot 3)$ & $119 \cdot 2$ & $117 \cdot 6$ & $118 \cdot 5$ \\
\hline $\mathrm{C}_{6} \mathrm{C}_{5} \mathrm{C}_{4}$ & $112 \cdot 8$ & $112 \cdot 4(112 \cdot 5)$ & $112 \cdot 8$ & $115 \cdot 0$ & $115 \cdot 1$ \\
\hline $\mathrm{H}_{7} \mathrm{~N}_{1} \mathrm{C}_{2}$ & $154 \cdot 8$ & $157 \cdot 3(158 \cdot 3)$ & $157 \cdot 1$ & $143 \cdot 5$ & $126 \cdot 4$ \\
\hline $\mathrm{O}_{8} \mathrm{C}_{2} \mathrm{~N}_{3}$ & $121 \cdot 4$ & $119 \cdot 0(118 \cdot 6)$ & $120 \cdot 1$ & $117 \cdot 2$ & $119 \cdot 3$ \\
\hline $\mathrm{H}_{9} \mathrm{~N}_{3} \mathrm{C}_{2}$ & $116 \cdot 1$ & $117 \cdot 0(117 \cdot 5)$ & $117 \cdot 8$ & $117 \cdot 7$ & $118 \cdot 3$ \\
\hline $\mathrm{O}_{10} \mathrm{C}_{4} \mathrm{~N}_{3}$ & $119 \cdot 5$ & $121 \cdot 0(121 \cdot 0)$ & $117 \cdot 0$ & $121 \cdot 0$ & $117 \cdot 0$ \\
\hline $\mathrm{O}_{11} \mathrm{C}_{5} \mathrm{C}_{4}$ & $123 \cdot 5$ & $123 \cdot 1(122 \cdot 8)$ & $123 \cdot 5$ & $121 \cdot 5$ & $122 \cdot 0$ \\
\hline $\mathrm{O}_{12} \mathrm{C}_{6} \mathrm{~N}_{1}$ & $100 \cdot 5$ & $103 \cdot 4(105 \cdot 0)$ & $104 \cdot 1$ & $118 \cdot 6$ & $113 \cdot 0$ \\
\hline
\end{tabular}

Dihedral angles $\left(^{\circ}\right)$

\begin{tabular}{lrcrrr}
$\mathrm{C}_{4} \mathrm{~N}_{3} \mathrm{C}_{2} \mathrm{~N}_{1}$ & $0 \cdot 0$ & $0 \cdot 0(-0 \cdot 1)$ & $0 \cdot 0$ & 0.0 & $-0 \cdot 4$ \\
$\mathrm{C}_{5} \mathrm{C}_{4} \mathrm{~N}_{3} \mathrm{C}_{2}$ & $0 \cdot 0$ & $0 \cdot 0(0 \cdot 3)$ & $0 \cdot 0$ & 0.0 & $0 \cdot 0$ \\
$\mathrm{C}_{6} \mathrm{C}_{5} \mathrm{C}_{4} \mathrm{~N}_{3}$ & $0 \cdot 0$ & $0 \cdot 0(0 \cdot 0)$ & $0 \cdot 0$ & 0.0 & $-0 \cdot 2$ \\
$\mathrm{H}_{7} \mathrm{~N}_{1} \mathrm{C}_{2} \mathrm{~N}_{3}$ & $180 \cdot 0$ & $180.0(-177 \cdot 3)$ & $180 \cdot 0$ & $-143 \cdot 9$ & $-145 \cdot 7$ \\
$\mathrm{O}_{8} \mathrm{C}_{2} \mathrm{~N}_{3} \mathrm{C}_{4}$ & $180 \cdot 0$ & $180 \cdot 0(180 \cdot 0)$ & $180 \cdot 0$ & $180 \cdot 0$ & $179 \cdot 8$ \\
$\mathrm{H}_{9} \mathrm{~N}_{3} \mathrm{C}_{2} \mathrm{~N}_{1}$ & $180 \cdot 0$ & $180 \cdot 0(-179 \cdot 7)$ & $180 \cdot 0$ & $180 \cdot 0$ & $179 \cdot 8$ \\
$\mathrm{O}_{10} \mathrm{C}_{4} \mathrm{~N}_{3} \mathrm{C}_{2}$ & $180 \cdot 0$ & $180 \cdot 0(-179 \cdot 7)$ & $180 \cdot 0$ & $180 \cdot 0$ & $180 \cdot 1$ \\
$\mathrm{O}_{11} \mathrm{C}_{5} \mathrm{C}_{4} \mathrm{~N}_{3}$ & $180 \cdot 0$ & $180 \cdot 0(-179 \cdot 9)$ & $180 \cdot 0$ & $180 \cdot 0$ & $179 \cdot 8$ \\
$\mathrm{O}_{12} \mathrm{C}_{6} \mathrm{~N}_{1} \mathrm{C}_{2}$ & $180 \cdot 0$ & $180 \cdot 0(-179 \cdot 0)$ & $180 \cdot 0$ & $180 \cdot 0$ & $179 \cdot 3$ \\
\hline
\end{tabular}

${ }^{\mathrm{a}}$ See figure 1. Values in parentheses are the AM1 solution phase parameters

(iv) Again the mechanism of solvent participation is the extraction of the proton by the water molecule, resulting in the formation of a hydronium ion (valency of water oxygen $=2 \cdot 56$, charge on $\mathrm{H}_{3} \mathrm{O}^{+}=0.908$ ), after which it transfers a hydrogen to the oxygen atom. Compared to the previous case, however, this transition state occurs slightly earlier on the reaction path, as the $\mathrm{O}_{12}-\mathrm{H}_{w}$ bond distance is larger $(1.825 \AA)$ and 
the bond order is only 0.059 in the transition state (see figure 1) as compared with the value of 0.212 for the $\mathrm{O}_{8}-\mathrm{H}_{w}$ bond order in TS1. $\mathbf{H}_{2} \mathbf{O}$. Therefore, in this case, the transition state is more like two separate entities, the alloxan deprotonated anion and a hydronium ion, united by hydrogen bonding. Thus, the proton transfer proceeds by a dissociative mechanism as in acid-base equilibria. As a result, the imaginary frequency for the process also reduces considerably (see table 3 ). This nucleophilic attack by water is confirmed by the decrease in the electron affinity on water complexation from $2.051 \mathrm{eV}$ to $0.951 \mathrm{eV}$.

(v) Since the dipole moment of the transition state is quite small, bulk dielectric effects do not bring about any relative energy lowering and the gas and solution phase activation barriers for the bare molecules are similar (see table 4).

\section{Conclusions}

Our calculations have shown the following.

(i) The charge transfer interactions indicate that the entity that migrates is a proton and not a hydrogen atom.

(ii) The four-membered ring transition states for the direct processes are highly strained and lead to high activation barriers.

(iii) However, the involvement of even a single water molecule reduces the barrier to a plausible level. The reasons are the release of strain due to the formation of sixmembered rings, and also resonance stabilization. The mechanism also changes to almost a two-step process entailing first the extraction of the proton by a nucleophilic attack by water, resulting in the formation of the transition state, followed by the transfer by water of one of its own protons to the oxygen.

(iv) Bulk solvent dielectric effects reduce the activation barrier for the transformation to the 2-hydroxy tautomer (II), but have insignificant effect on the corresponding values for the other tautomer. Dipole moments seem to be the important criteria governing the stability of the various structures.

\section{Acknowledgement}

One of the authors (VK) thanks the Council of Scientific and Industrial Research, New Delhi for a fellowship.

\section{References}

1. Michel A G, Trudel Y and Dion C 1993 Int. J. Quantum Chem. 46183

2. Adamo C, Barone V, Lioson S and Minichino C 1993 J. Chem. Soc., Perkin Trans. 2697

3. Nimlos M R, Kelley D F and Bernstein E R 1989 J. Phys. Chem. 93643

4. Barone V and Adamo C 1994 J. Comput. Chem. 15395

5. Kakkar R and Sarma B K 1997 Indian J. Chem. B36 1148

6. Dewar M J S and Thiel W 1977 J. Am. Chem. Soc. 99 4899, 4907

7. Dewar M J S, Zoebisch E G, Healy E F and Stewart J J P 1985 J. Am. Chem. Soc. 1073902

8. Stewart J J P 1989 J. Comput. Chem. 10209

9. Stewart J J P 1991 MOPAC Program Package 6.12, QCMP 137, Bloomington, IN

10. Baker J 1986 J. Comput. Chem. 7385

11. Klamt A and Schuurmann G 1993 J. Chem. Soc., Perkin Trans. 2799

12. Kakkar R and Sarma B K 2000 Indian J. Chem. B39 103 
13. Swaminathan S, Craven B M and McMullan R K 1985 Acta Crystallogr. B41 113

14. Bell R L and Truong T N 1994 J. Chem. Phys. 10110442

15. Karelson M, Katritzky A R, Szafran M and Zerner M C 1989 J. Org. Chem. 546030

16. Cramer C J and Truhlar D G 1994 Theor. Chim. Acta 19 